Please do not remove this page

RMIT

UNIVERSITY

\title{
Should we smoke it for you as well? An ethnographic analysis of a drug cryptomarket environment
}

Kowalski, Michala; Hooker, Claire; Barratt, Monica

https://researchrepository.rmit.edu.au/esploro/outputs/9921861063801341/filesAndLinks?institution=61RMIT_INST\&index=null

Kowalski, M., Hooker, C., \& Barratt, M. (2019). Should we smoke it for you as well? An ethnographic analysis of a drug cryptomarket environment. International Journal of Drug Policy, 73, 245-254.

https://doi.org/10.1016/j.drugpo.2019.03.011

Document Version: Accepted Manuscript

Published Version: https://doi.org/10.1016/j.drugpo.2019.03.011

Repository homepage: https://researchrepository.rmit.edu.au

CC BY-NC-ND V4.0

(C) 2019 Elsevier B.V. All rights reserved.

Downloaded On 2023/04/26 17:40:42 +1000 
Title: Should we smoke it for you as well? An ethnographic analysis of a drug cryptomarket environment

Authors: Michala Kowalski ${ }^{12}$, Claire Hooker ${ }^{1}$, Monica J. Barratt ${ }^{2} 34$

Authors Affiliations:

1. Centre for Values, Ethics and Law in Medicine, University of Sydney, Sydney, NSW, Australia

2. Drug Policy Modelling Program, National Drug and Alcohol Research Centre, UNSW, Sydney, NSW, Australia

3. National Drug Research Institute, Faculty of Health Sciences, Curtin University, Perth, WA, Australia

4. Behaviours and Health Risks Program, Burnet Institute, Melbourne, VIC, Australia

Corresponding author: Michala Kowalski, m.kowalski@unsw.edu.au

Word Count: 8260 (not including abstract)

Funding Sources: The work received \$1000 AUD from The University of Sydney to support the Independent Research Project.

Declarations of Interest: None 
Title: Should we smoke it for you as well? An ethnographic analysis of a drug cryptomarket environment

\begin{abstract}
:
Introduction: Why aren't cryptomarkets more widely used? Researchers from a wide array of fields have attempted to answer this question by studying the size of drug cryptomarkets, the substances trafficked, and their structure. In this paper we address the potential acceptance of drug cryptomarkets by studying their perceived ease of use.

Methods: This paper draws on observational data collected over 350 hours of unstructured observation during an ethnographic study conducted in April-September 2016 of the two most prominent drug cryptomarkets at the time, in addition to seven face-to-face semistructured qualitative interviews.

Analysis: Use of cryptomarkets relies on specialised knowledge. The administrators of the cryptomarkets do not play a publicly visible role in facilitating or easing cryptomarket use while simultaneously expecting cryptomarket users to exhibit self-reliance. We argue that the current levels of complexity and obfuscation constructed in the cryptomarket environment act as a barrier to the widespread acceptance of this technology.

Discussion: Through studying cryptomarkets' potential for widespread use we have shed light on current barriers to their growth: requirement of specialised knowledge in order to use cryptomarkets and no public efforts to bridge the knowledge gap on behalf of cryptomarket administrators. As cryptomarkets continue to develop the ease of use of these platforms are bound to change, and with them the likelihood that cryptomarket usage may increase.
\end{abstract}

Keywords: cryptomarkets; liminality; ethnography; technology-acceptance; self-reliance. 


\section{Introduction}

Cryptomarkets have exhibited rapid growth (Tzanetakis, 2018) since the launch of the progenitor Silk Road in 2011 by Ross Ulbricht and fellow developers, who reportedly were more familiar with communication and encryption technologies than with traditional drug markets (Bearman \& Hanuka, 2015). To date they remain quite small in market share compared to the drug trade at large. Estimates for cryptomarket turnover ranged from $\$ 170-$ $\$ 300$ million USD annually for 2016 (United Nations, 2018), while the global drug trade turnover was estimated to be between $\$ 426$ - $\$ 652$ billion USD in the same year (May, 2017). Given the belief that drug cryptomarkets can circumvent traditional trade routes, law enforcement strategies, and the drug retail market (Aldridge \& Décary-Hétu, 2015; Griffiths \& Mounteney, 2017) in a cultural moment of legal e-commerce edging out brick and mortar retail (Klara, 2017), it is worth questioning if and how cryptomarkets will continue to grow. Do they have the capacity to scale up to become a major distribution mechanism?

Researchers from a wide array of fields such as criminology (Martin, 2014), sociology (Bancroft, 2017), public health (Aldridge, Stevens, \& Barratt, 2017), forensic science (Broséus, Morelato, Tahtouh, \& Roux, 2017), and geography (Dolliver, Ericson, \& Love, 2018) have all produced work around questions like these by studying the size of drug cryptomarkets (Paquet-Clouston, Décary-Hétu, \& Morselli, 2018), the substances trafficked (Van Buskirk, Naicker, Roxburgh, Bruno, \& Burns, 2016), and their structure (Demant, Munksgaard, \& Houborg, 2018). These studies found the cryptomarkets functioning despite multiple publicised law enforcement operations (Décary-Hétu \& Giommoni, 2017), and geographically situated and catering to the 'last mile', i.e. the end user (Aldridge \& Décary-Hétu, 2016).

Our work builds on these studies by addressing a key element of the viability of drug cryptomarkets: their potential acceptance. The field of Information Technology Sciences studies the potential acceptance of services or platforms. Acceptance is commonly described as dependent on many factors: the service or product on offer and its merits, the local environment, the ease of access to the service, and the ease of transitioning to using the service or platform. The Technology Acceptance Model (TAM) is widely used as a predictive model for whether a technology will be accepted. It is reliant on two variables: perceived usefulness and ease of use (Venkatesh \& Davis, 2000). Our paper focuses on the ease of use of cryptomarkets, but we note that the perceived usefulness of the cryptomarkets is closely related to the ease of use, for if the technology is deemed too difficult to use its perceived usefulness will drop in tandem. Previous research has likened cryptomarkets to other more familiar e-commerce platforms such as eBay (Barratt, 2012) or Amazon (Aldridge, DecaryHetu, 2014) and have described the cryptomarkets as user-friendly interfaces (Clouston Paquet, 2017). Whilst we agree that cryptomarket users may describe the market interfaces themselves as user-friendly, we argue that accessing and navigating the cryptomarket environment requires complex networks of understanding and pre-existing knowledge.

\section{Theoretical Underpinnings}

The philosophy of Self-Reliance, first published by Emerson in 1841, is at the root of modernday libertarianism, the ideological justification used by Ross Ulbricht for founding Silk Road (Mac, 2013; Sotirakopoulos, 2017). Self-reliance is the idea of relying on one's self for ethical and moral guidance (and action); practicing non-conformity, solitude, and not recognising the authority of others over the self (Emerson, 1902). Self-reliance and other libertarian values such as personal freedom are described as culturally-embedded positions associated with cryptomarkets (Maddox et al., 2016) as they played an integral role in the justifications presented by Ulbricht for founding Silk Road. 
The concept of liminality stems from the work of ethnographer Arnold Van Gennep, who in 1909 wrote his thesis Rites of Passage (Van Gennep, 2013) in which he constructed many of life's milestones as rites of passage: ritualistic transformations from one identity or role to another. The transitionary process is divided into three linear stages: separation, liminal stage, and incorporation. In the 1960s Victor Turner introduced the work of van Gennep into the modern world, focusing especially on liminality (Turner, 1987): the ambiguity or disorientation that comes with being in-between identities. Liminality and rites of passage are theoretically tied to the concept of community. There is an ongoing discussion in the literature about the degree to which markets and market places can be thought of as akin to communities (Maddox, Barratt, Allen, \& Lenton, 2016), or can host communities within them (Boon, Pitt, \& Salehi-Sangari, 2015; Ladegaard, 2017). It is beyond the scope of this paper to contribute to this discussion about markets and communities; however, we acknowledge that community is an integral part of the model and liminality. The concept of liminality in a cryptomarket environment is the focus of our work here, rather than weighing in on concepts such as rites and communities.

What follows is our analysis of the ease of use of cryptomarkets by examining how concepts such as liminality and self-reliance are constructed in the cryptomarket environment. We argue accessing and navigating the cryptomarkets requires knowledge and resources, making for an effective barrier to the widespread acceptance of this technology by greatly affecting the ease of use and therefore the perceived usefulness of drug cryptomarkets.

\section{Methods}

This paper analyses data collected during a larger non-participatory observational ethnography of a cryptomarket environment. As the cryptomarkets are hosted online, the ethnography was designed to study the online spaces which constitute the cryptomarket territory including the cryptomarkets and related fora coupled with face-to-face interviews with participants who have a history of cryptomarket engagement. MK engaged in roughly 350 hours of unstructured observations carried out over a period of seven months starting in April 2016, alongside seven semi-structured face-to-face qualitative interviews with participants who were recruited via personal networks and snowballing, averaging at 60 minutes per interview. Interview participants were residents of Sydney and Melbourne, Australia; age ranged between 19 and late 40s; women and men, straight and LGBTQI-identifying, from diverse cultural heritages and backgrounds. Interview participants had varying degrees of experience with the cryptomarkets: two of the participants were intermediary buyers, i.e. they supplied money to someone else to purchase drugs for them from cryptomarkets, two other participants had stopped purchasing drugs entirely from cryptomarkets by the time of their interview (one after two purchases, the other after an extensive purchasing history), while the remaining three participants were active cryptomarket buyers at the time of their interview. To map out and observe the world that the interview participants operated in, the study was designed to recruit interview participants first and subsequently enter the field. The behaviour of the participants dictated the sites of inquiry which were included, except for various cryptocurrency related sites which were not included in the study. The field also included sites that were frequently referenced at sites already included for observation, resulting in a mix between sites hosted on the darknet and sites hosted on the clearnet (as the Internet is commonly referred to on the darknet). Observations were carried out at the two highest rated drug cryptomarkets at the time, the complementary drug cryptomarket fora hosted on the darknet, the complementary drug cryptomarket fora hosted on the clearnet, and related subreddits such as /darknetmarkets, the hub, and the darknet market avengers. This translated into roughly a thousand ethnographic documents, capturing data generated by more than 227 contributors delineated via unique usernames across the fora and trading sites, 
dozens of field notes, and user profiles constructed from information that fora users shared on the fora. Fora contributors were observed to be predominantly from English-speaking backgrounds, predominantly male, engaged in steady employment, with varying degrees of technical expertise, cryptomarket experience, and drug taking experience. They were observed to have different interests which they were pursuing in their contributions to the fora including: technical expertise, drugs, cryptomarket experience, harm reduction, online safety (referred to as opsec or operational security), policing and law enforcement, and stigma.

The ethnographic practice of memo writing as formulated by Emerson, Fretz and Shaw (Emerson, Fretz \& Shaw, 1995) and Charmaz (Charmaz 2014) as an analytical tool to link observations with interpretations was essential both to the study and to the genesis of this paper. Reading through her analytic memos while looking for new lines of inquiry in the field, MK identified that she had been irritated by a set of seemingly non-generative posts. A feeling she perceived as shared with some fora contributors, such as s':

"Listen...the forum is full of posts from guys like you complaining about being scammed but you don't stop to THINK".

[emphasis in bold our own]

Or as enacted in the signature of forum contributor d':

"Don't contact me with novice questions. I won't answer them".

This process allowed for the space to identify these 'non-generative' posts as an interesting subset of data and to concentrate on the peculiarities of these posts, the unique reactions they elicited from fora contributors, and to consider their relationship to the concept of liminality.

MK engaged in multiple coding rounds of the pooled interview transcriptions and written exchanges from the fora datasets as common in ethnographic methodologies (Charmaz \& Olesen, 1997; Roper \& Shapira, 2000; Morse, 1994) using thematic analysis (Braun \& Clarke, 2013), starting from open coding building towards axial coding, and finally themes. The coding rounds were guided by analytical questions, such as what makes one person use the cryptomarkets and another not? What is needed to use a cryptomarket? How does one use a cryptomarket? $\mathrm{CH}$ and MJB supervised the research project as well as contributed to its conceptualisation and the revision and editing of this paper.

Ethics

The ethics of non-participatory observational studies in ethnography have long been debated (Page \& Singer, 2010) and Martin and Christin's work on the ethics of cryptomarket study in particular have also called for a move towards negotiated access whenever possible (Martin \& Christin, 2016). It is beyond the scope of this paper for us to enter into this discussion extensively however, we believe it merits future study. For our purposes we view the web (clearnet) and onion (darknet) sites included in the study as public (noting that encryption renders onion sites anonymous not private) and the correspondences that occurred on them as correspondences in the public domain. Accordingly, no data was collected from invite-only fora or marketplaces. Quotes taken from fora correspondences have been slightly altered as recommended by Sixsmith and Murray (Sixsmith \& Murray, 2001) when quoting posts from public sites. Quotes from interviews have been edited for clarity. Interview participants' names have been replaced with pseudonyms; and the unique usernames used on the range of fora and market sites included in this study have been replaced with a character(s) from the alphabet. Ethics approval for this study was granted by the University of Sydney's HREC. 


\section{Analysis}

We constructed a total of six themes that pertain to the ease of use and growth potential of the cryptomarket environment: self-reliance, segregation, research, window shopping, spread the word, and liminality. In broad terms accessing a cryptomarket requires pre-existing knowledge and the correct technological tools. These descriptive themes move beyond recounting instructions on how to access cryptomarkets, instead explicating the processes we found to be involved in establishing a cryptomarket practice. While the themes are distinctive there are clear relationships in the data between the different themes which we explore in the discussion section.

\section{Self-reliance}

Drawn from observations, interviews and fora data, our theme of self-reliance has multiple constructs that are fundamental to the cryptomarket environment. The cryptomarkets that were observed at the time of the research did not host instructions, guides, or tours of the websites in a publicly visible manner. The landing page for these websites is a login page, requiring registration prior to accessing the markets themselves. These markets did not host detailed instructions of how the markets work or what you will need to place an order; nor did they offer helpful tips about how to get the most out of their website. This information was hosted on an array of other websites, in the form of tutorials, videos and discussions. The individuals who uploaded this content identified themselves, when they purported to selfidentify, as researchers, buyers, vendors, or interested parties, but not as directly affiliated with the administration of any one cryptomarket. Learning how to use a cryptomarket is then left to the coordination, discretion and direction of the interested individual, in the visible absence of an overarching coordinated socialising effort. A conversation between I' forum moderator, and $\mathrm{OO}^{\prime}$ describes a transference of the responsibility of institutional knowledge sharing from the cryptomarket bodies to the people who use cryptomarkets (emphasis in bold our own):

l': oO' we all know how time poor site administrators and moderators can be and if you offer a bit of help to new people it can help keep the site running, and we all do our part.

oO': We all want the same thing man. For people to be able to buy and sell safely on this marketplace. I'm just a member who happens to have some free time and wants to help.

In the absence of a centralised guiding effort individuals will need to find information sources for themselves. This includes which guide or guides to seek out and how many of them to read and engage with, as well as how many steps in the process they would like to follow. Is the cryptomarket address enough? Should they acquire a brand new cryptomarket-dedicated computer? Install a completely new operating system? Learn about cryptography? Find out how to launder bitcoin? Engage in learning about other cryptocurrencies to convert back and forth along the way? How much do they need to learn before they are ready? What does ready look like? What are reasonable expectations and what are not? Do they need to read about the etiquette of what will be expected of them and how the entire process will work or simply concern themselves with technical details alone? These are all decisions and judgements they will have to make on their own. These processes can be lengthy or short. What is read is up to the individual, as there are many options. Interview participants had different experiences of these questions: David found the information presented in an article in a daily newspaper sufficient, while Al and Matt had both been using Tor and Bitcoin for a few years before investing resources into learning how to purchase drugs from the darknet markets. 
The next construct of self-reliance we would like to discuss is the performative self-reliance of actors in the cryptomarket environment. This performative self-reliance includes the centring of the self while simultaneously discounting the work of others that went into the making of the materials, sites, reviews, and all other elements of the environment the actors find themselves in. For example, in these excerpts from Kyle's and Matt's interviews they both minimize the roles of others in their journey towards establishing a cryptomarket practice:

MK: And did he help you at all in getting set-up?

Kyle: Yeah, he explained how to get Bitcoin. Because I was a bit confused about the whole process. But everything else was my research. There are detailed websites that show you step by step what to do.

Matt: I had some older friends on [a gaming platform] and they were just talking about how the darknet worked and how there's all kinds of stuff - basically anything that's illegal is on there. And within ten minutes, after a five-minute conversation, I had downloaded Tor and I was using the darknet and I had gotten on to Silk Road. I was around 13 or 14, back then I didn't even care about drugs, I was a kid. It was just the bitcoins that interested me because at the time bitcoins were like 15 dollars a coin and after my friends told me how much they fluctuated I begged my parents to let me invest...

MK: Did anyone help you go through the process at the beginning?

Matt: There was no one who helped to me to do anything at all. Like I had friends who told me about the deepweb, and who told me what bitcoins were.

Interview participants and fora contributors alike were engaging with instructions specifically designed to assist them in their socialisation process. This emphasis on their own efforts combined with the simultaneous absence of a discourse of recognition of the efforts of others in accommodating their own processes is more indicative of a fashioning of events in line with the ethos of self-reliance than of a truly independent process.

\section{Segregation}

Our theme of segregation was constructed from a combination of observations, interviews and fora data. Segregation includes a technological segregation of software, (e.g. installing cryptomarket dedicated software) or of hardware (e.g. hardware which is dedicated to cryptomarket use), an identity segregation (e.g. encouraging actors to use a tailor-made identity for cryptomarket usage) and a taxonomy of the different products trafficked and threads of interest. The segregation involved in the technological and taxonomical aspects of the cryptomarket environment is largely structural, i.e. these are intentional features of the cryptomarkets. By design cryptomarkets are hosted on the darknet. By design the darknet is accessible only via dedicated browsers such as Tor and I2P. The taxonomical aspect is also structural as it conforms with the platform type selected to model the cryptomarkets on, a model that is organised around the goods being traded. Drug cryptomarkets are organised around taxonomies of drugs. Therefore, each drug is presented in isolation. In his interview Matt explains:

Matt: So when l'd go to [cryptomarket] it would say forums in the top right corner of the screen and I could click that and it would take me to forums, but I'd never bother because it wasn't something I was interested in. And the way you'd search for all your drugs is on the left side of the screen is a little drop box, has 
everything in it, cannabis, dissociatives, psychedelics; You click each section it drops down more drugs, more drugs, more drugs; Hardware, equipment, all kinds of stuff.

\section{I: And then next to the product you've got what?}

Matt: Once you click what you're looking for, you find what you're looking for. So if I was looking for cannabis l'd click cannabis and then once you'd click cannabis it would come up with edibles, hash, oils, flower (as in just plant material). And then you can just click that and then you can search through different listings. It's like eBay: you search the item you want, you scroll down, there's all the listings you want with the price next to it.

The forums are also segregated taxonomically according to categories determined by the cryptomarket administrators. See figure 1.

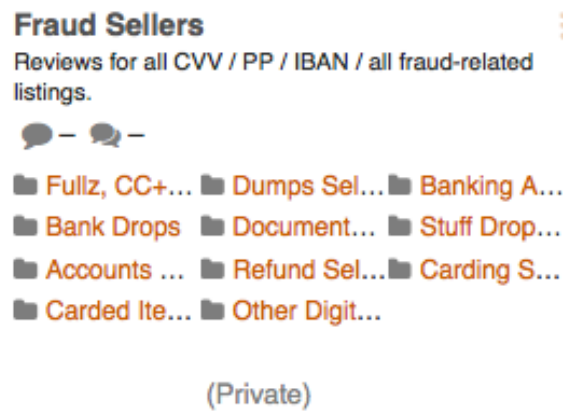

(Private)

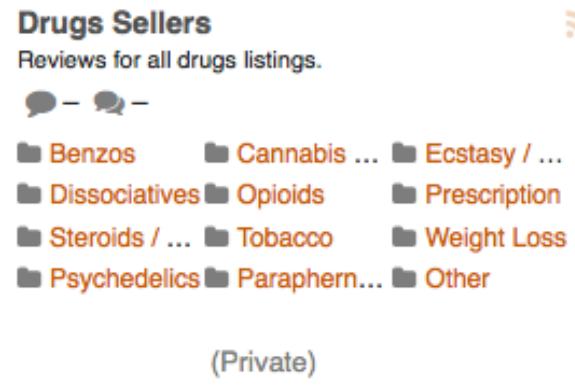

Hosting/Security/Spam/Traffic Sellers Reviews of Hosting, VPNs, Socks providers, spam sellers, trafic sellers etc.

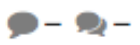

- Security S... v VPN Sellers - Socks/SS... - Call Servic... U Spam Sellerst Traffic/lnst... - Hackers F...

(Private)

figure 1, forum categories.

Organising the marketplace according to products as opposed to organising according to vendors means that at first glance the rest of a vendor's wares, if they exist, are hidden. Segregating the forums from the markets results in fora use as a choice, not necessarily as a requirement. Segregating the forums according to categories and then threads creates segregated spaces, potentially distancing different sets of cryptomarket actors from each other (e.g. carders from hackers, hackers from drug buyers etc.). Segregating threads according to taxonomies of drugs has much the same result. Curiously this contributes to a stigmatisation of heroin, crack-cocaine, and methamphetamine users, while also creating relatively safe 
spaces for them on dedicated threads. See the juxtaposition of these two effects in two different threads including the same participant $A^{\prime}$, in the one contributing to stigma around drug use, and in the other opining on the utility of forums as judgement free spaces for stigmatised drug users (emphasis in bold their own):

oO': I'd be a classy junkie that paid (amount) a hit. Not doing $\mathrm{H}$.

A': lol, you won't be paying (amount) for long if you stayed a junkie! Keep classy and keep off it.

oO': I figure if I shell out that much I can tell myself hey l'm a classy junkie. Just like all users say to themselves, hey at least I'm not a crackhead.

$A^{\prime}$ : aB', I found your thread on [forum] and backed you up, for what it's worth.

I'm still in the 'Beginner's' stage, but happy to help with this, if needed I and plenty of others would LOVE an actual community. Particularly with stigmatised drugs (heroin, meth, crack) users are forced to hide their use and online forums can be a place to socialise without judgement.

\section{Research}

Research in the emic sense refers to active information collecting practices; determining who or what is a trust-worthy source; and what information will be needed for the task at hand: learning to use a cryptomarket. We constructed this theme based on interviews and fora data. Research is performed before making a purchase from a new vendor, or a new type of drug, or a new cryptomarket and any or all of the above. In his interview Al explained:

Al: I had to do a lot of research before I could make my own purchase. I spent a lot of time reading about how the Tor network actually works. Understanding that, learning. I had a basic understanding of encryption but not enough. So, I just thought l'd top up on that. I did a lot of research on how encryption works, how PGP keys worked. That took me about two or three days to understand. I got set up. Got a clean laptop. Used TAILS, very secure, fresh, operating system, installed Tor; started looking through different marketplaces, picked one; set-up an account; made sure that the account name had nothing in common with any of my clearnet accounts, nothing to do with, you know, Facebook or anything like that. [Used] different big passwords, as much as I could. I took every possible precaution that I could think of, or that was recommended to me.

\section{MK: Recommended by who?}

Al: By my friend, by online forums, a lot of just common sense. Like don't use your real name, for example. I think I took more precautions than was probably necessary. These things: better safe than sorry.

Al's account helps define our construct of research as bound by purpose, scope and time. He touches on all three dimensions, defining his goal, to learn how to make a cryptomarket purchase, the scope, choosing to include the technological tools used in the environment, the different cryptomarkets and their associated behavioural practices, and the time involved, which included at least 3 days dedicated to the learning process itself. 
This excerpt is also a prime example of the relationships between the different themes we have constructed to describe the cryptomarket environment. In this case our themes of segregation and research are interlaced, feeding in to each other. New pieces of technological hardware, software, and new accounts with electronic services are described in terms of "clean, secure, fresh, different, [having] nothing in common" emphasizing the segregation. The research described is also segregated as it is also cryptomarket-specific research.

This process of self-directed research to use a commercial platform is uncommon in mainstream technological services intended for mass adoption. The mere thought of studying and reading can be enough to put off people from engaging with the cryptomarkets. Priya discusses why she buys drugs from the cryptomarkets indirectly through a friend instead of engaging with the cryptomarkets directly herself:

Priya: maybe I think I can't be bothered doing it and I think maybe one reason is probably cause it's not like a direct thing. It's not straight forward. So I know I have to spend at least an hour or two trying to figure it out, it's not an easy thing to do. So that's why I find it easier to just get someone to do something for me.

Priya was not the only participant who used the cryptomarkets indirectly rather than directly. Consider Jess's case, an interview participant who had expected to be able to execute her first cryptomarket purchase during her first cryptomarket experience on a whim:

Jess: We, my house, like everyone in my house really wanted to do something [drugs] one night, I think we were probably a little bit drunk when it started and one of my friends who I live with, who I used to live with, is very into that kind of stuff. He's told me about some of the porn that he's got to and stuff (and I find it revolting); but he's interested in bitcoin and bitcoin mining; and he's interested in what's out there in the darknet. And so he was like "we should try it", and so we were on my computer and we sort of found some vague websites. I don't think we were going about it the right way [laughs] and it just sort of fizzled out. I guess we couldn't really work out how to do it, it was too complicated and none of us, even though one of my roommates is an engineer, one of them is a computer science major and one of them is the one who's like really interested, and I'm like ok at technology, like I work in technology... And the four of us like were sitting there and could not figure it out; and then the longer we spent doing it the less I trusted it.

MK: which, sorry but what like what was the obstacle? So you already had bitcoin?

Jess: Yeah so the bitcoin guy already had bitcoin, yeah it was the actual just finding the sites. So we were on some places but they just didn't seem legit at all.

Approaching the cryptomarkets as an exercise solely in e-commerce did not lead to promising results in Jess' experience. It is worth asking what exactly went wrong. Between the four of them, they had technical aptitude and the technological and monetary means. What they did not have was knowledge: which cryptomarkets to use, which to avoid, and how it will work once you do choose one? What they did seem to exhibit in abundance was self-reliance: "even though one of my roommates is an engineer, one of them's a computer science major and one of them's the one who's like really interested, and I'm like ok at technology, like I work in technology". As important as self-reliance may be to the narrative of using cryptomarkets, 
researching (in the emic sense) information created and disseminated by others is also clearly a key part of this process.

\title{
Window-Shopping
}

This theme draws on data from interviews and fora data. The practice of "window-shopping" was described by interview participants and prolific fora contributors alike. Much akin to the brick and mortar consumer behaviour of walking by and into stores to inspect what is available, but not making any purchases at that time, cryptomarket window shoppers will visit the cryptomarkets and related fora to read reviews and recommendations for products and vendors alike without engaging in purchasing during that specific visit. In a cryptomarket forum thread, $A^{\prime}$ describes window shopping on the cryptomarkets:

A': I prowl around the markets when not looking to buy, out of general interest in drug trends or 'window shopping' and the side effect is noticing who sticks around, who suddenly disappears, and getting a feel for the style of different listings.

In his interview Al describes window shopping on the fora:

\section{MK: And the reddit forums?}

\begin{abstract}
Al: I've looked at them. Yes, I go on them...I mean I go on there when I'm looking for, say, a new vendor. Sometimes you'll see vendor reviews, where people post really detailed information about quantity, purity, and if they had it tested by a professional. Their general trip reports, how it felt, what it was like, whether they'd go back. So I go through that, just kind of like window shopping I guess. If it's about something I'm interested in I'Il read about it, check if they mention the countries [they] deliver to, if they mention anything that really intrigues me; and if I like it l'Il save it for later, and I'll come look into it when the time comes.
\end{abstract}

Window-shopping as described is concentrated specifically on the cryptomarket environment: Which vendors are operating on the cryptomarkets? What are they selling there? What did the reviewers have to say about the vendor and the drug/s? Both A' and Al describe their windowshopping practice as being driven by interest and habit. It is interesting to note that the practice of window-shopping, while common in legal markets, would most likely not be possible as a regular practice associated with drug buying in the 'last mile' outside of a cryptomarket context. This is due to both the concentration of multiple vendors and therefore offerings at one site, and the spatial and temporal disconnect between the act of perusal and the act of purchase afforded by the online nature of the interaction. Neither of these conditions are present in faceto-face drug buying. The distinction between research (the theme) and window-shopping is a temporal and contextual one. Research as a practice is associated with novelty and tied towards an immediate goal: accessing a cryptomarket, acquiring a cryptocurrency, making a purchase of cocaine from a new vendor. Window-shopping is described as a repetitive practice that is conducted at the window-shopper's leisure. Where research is finite and goal-oriented, window-shopping is ongoing and seemingly aimless. It is worth considering whether the two practices are as distinct as they are constructed to be and whether window-shopping is indicative of the continuous need for research in an established cryptomarket process.

\section{Spread the word}

This theme stems from practices described in fora data and interview data. While online and face-to-face constructs differ, the practice essentially involves a cryptomarket user introducing 
others to cryptomarkets. The online practices were actively encouraged by the cryptomarkets we observed, as they offered actors an incentive-based scheme called referrals: in exchange for spreading the word of cryptomarkets you will receive bitcoin in your market wallet.

tl' explained how the system worked for one of the cryptomarkets in a cryptomarket fora thread (emphasis their own):

tl': When your friend or affiliate FINALIZES a buy, your account gets credited with $25 \%$ of the amount [cryptomarket] takes off the top. When you click onto your balance it will show you deposits, withdrawals and commission for completed affiliate order which is what you made from a referral you have. [Cryptomarket] has been good about that.

It is worth noting that cryptomarket actors used the referral scheme in different ways. There were those who tried to recruit affiliates off of clearnet sites and therefore the recruits were presumably new actors, and there were those who used the system on cryptomarket fora instead. Note the conversation on a cryptomarket fora between r' and tl':

$r^{\prime}$ : I made a basic spambot that ran on a few chats, being on the clearnet $99 \%$ of the people were clueless what an onion website is and how to access it so was pretty useless. Only got me approx. 20 users/48 hours; To get the rest I spammed the shit out of [forums] and question/answer boards in the drug/markets section eight hours a day for two days (directing newbies looking for drugs to the right place so in a way it wasn't spam at all). That really worked well, but the admins on the boards I spammed my link on banned links because of that, if not that l'd still be doing it, because so far, it's the most efficient way l've found.

tl': It's tedious work hey? Try [forum]. The drug forums there are full of idiots.

This exchange of tutelage in exchange for commission is further explained by oO' (emphasis their own):

oO': If someone spends all this time helping you out, answering all your questions, guiding you through the process, the LEAST you can do is go through their referral link so they get a little thank you coin. It's not much, but it's nice to know people appreciate the time you spent.

Attempting to monetize assistance in navigating cryptomarkets is another consequence of the absence of the cryptomarket administrators themselves in the form of guides, introductory tours, live chat window or by maintaining an active presence.

We have constructed the face-to-face process of spread the word as a ritualistic presentation of the drugs purchased from a cryptomarket to a group of peers who use drugs. This was discussed in a few of the interviews, as well as in fora posts. This process can include a brief explanation of where the drugs are from, and a communal sampling of the drugs in question. It may occur in person, or it may take the form of sharing on the cryptomarket fora and the writing of extremely detailed reviews. Take Matt's and Al's descriptions of their first postpurchase experiences:

Matt: Once that happened I started to tell some friends at school about the deepweb and they thought it was the most amazing thing that had ever come into their lives. Holy shit you can buy drugs on the internet, we don't even have to get someone's number. We don't have to search for acid. 
Al: my best purchase would have been the first one, the one I got with my mate. Does that count?

MK: Yeah, of course.

Al: Yeah it was amazing. We got MDMA, it was really like nothing l'd seen before. We decided to take a lot we took umm basically we just hung out together a bunch of friends, decided to take some MDMA for about 12 hours. And it was one of the best experiences of my life. When we started out the group included a couple of very close friends, and a couple of friends that I only knew, we weren't best mates. For 12 hours we were just the five or the six of us talking. We had very quiet music, it was very nice, no one disturbed us, we weren't at a club or anything, just at someone's house hanging out. No sleep obviously, and we were just extremely honest. You know, you've got no inhibitions, you don't hide anything. You're just honest with people, and the whole euphoria, and I guess the sense of love and connection, it really had a tangible effect. The next day we were different friends than we had been before that; and since then these guys have been my closest friends.

Participants such as Matt, Kyle, Margo, and Al spoke of peers expressing positive reactions to the drugs, and excitement about the possibility of continued cryptomarket use. Peer reactions are not always positive though, and they can be critical of both the method of acquisition and the quality of the product. For example, David had a different experience with his friends remaining sceptical about using the cryptomarkets even after sampling the drugs:

MK: Do you know other people who use the cryptomarkets?

David: I don't actually. I'm the weird freak who had the gumption to do it. No one else, everyone else was a bit too paranoid.

MK: They knew about it?

David: Well I told them about it. Like check it out, this is great, here's the weed I got, smoke it! And they were like 'Yeah it's great!'. But none of them ever did it. [I stopped using the cryptomarkets] shortly after those two purchases because the price after Bitcoin conversion wasn't worth it anymore.

$A^{\prime}$, a forum contributor, in response to R' about whether or not black tar heroin gets people sufficiently high, lamented that her best friend preferred her own (street) supply to the supply that A' sourced from the cryptomarkets, and opined on the psychological processes that might be at play (emphasis her own):

$A^{\prime}$ : In the beginning I thought it was her higher tolerance (all the black tar heroin was bought by me and all the street dope bought by my friend, and we both got high together). But that doesn't explain why *I* found *her* stuff less potent than my stuff. And I had a different friend with super low tolerance try both types (sniffing). He agreed the black tar heroin was significantly stronger. I think it might be a placebo effect. Said friend has been in the game way longer than me and wants to lay claim to the best stuff in the city, while I naturally want to lay claim to discovering an untapped resource. Luckily, in the end, I bought an A grade batch and finally got her high, and her connect lifted their quality, getting me sufficiently high. Everyone's a winner. 
Margo, Kyle and Al all described establishing a cryptomarket practice after being introduced to cryptomarkets in this manner. Priya described establishing a practice as an indirect buyer (i.e. does not actively make the purchase herself) after a friend brought over drugs from a cryptomarket.

\section{Liminality}

Our theme of liminality draws mainly on observations, analytical memos, and fora data. The etymology of liminality or liminal is from the Latin word limen: a threshold. Liminality is the transitional and transformative part of a process, when and where the individual steps into the unknown (Turner, 1987). Cryptomarkets may be thought of as liminal spaces: an 'other' space disconnected from the material realities of drugs and drug sales. Cryptomarkets see the shift of the transactional nature of the drug purchase to a digitized environment. Some transactions can be marked as always in process due to a structural feature present in many cryptomarket transactions known as escrow. In an escrow process there are three parties to a transaction: the vendor, the buyer and the guarantor. The vendor and the buyer make an agreement and the currency is held by the guarantor until instructed to release the funds by the buyer. This process can be subverted by never declaring the goods as arrived and ordering the release of funds. This is often referred to as buyers scamming the vendors.

Even if this analogy is a conceptual step too far, cryptomarkets also play host to liminal interactions and lamentations. Liminal encounters are defined as encounters between individuals who are at the beginning of their transformation, and more experienced actors who have already completed their transformation. In the context of cryptomarkets this can include interactions between vendors and buyers, and interactions between fora contributors. See q's remark on a cryptomarket forum:

q': So being the [novice] I am; I did not research enough before buying a bunch of [subpar substances].

In this excerpt q' interacted with another actor, a vendor, who was able to sell q' drugs of a questionable quality according to q'. q' assigns responsibility for this asymmetry to themselves, for not having performed the required amount of research to navigate a space.

A minority of individuals perform liminality publicly on the cryptomarkets and cryptomarket related fora. van Gennep observed that interactions during the liminal period are not always pleasant. The same can be said about interactions we have classified as liminal which were observed on the cryptomarket fora. The public reactions an actor will garner from the established cryptomarket buyers will depend on their own behaviour, the behaviour of the established buyers, and the state of the forum they are posting in. Spam is truly everywhere in our society and spam is ever-present on the cryptomarket fora. The fora have moderators whose work includes maintaining the forum and relegating the spam to the trash posts. sK' notes on a cryptomarket forum:

sK': Ok so... noticed the forums getting all spammy, then the market got really choppy and I thought "fuck this, I'm outie" ... I'm glad it was only a DDOS and nothing more sinister... Glad to see the integrity here is exactly what I had come to believe.

The spam posts look like this: 


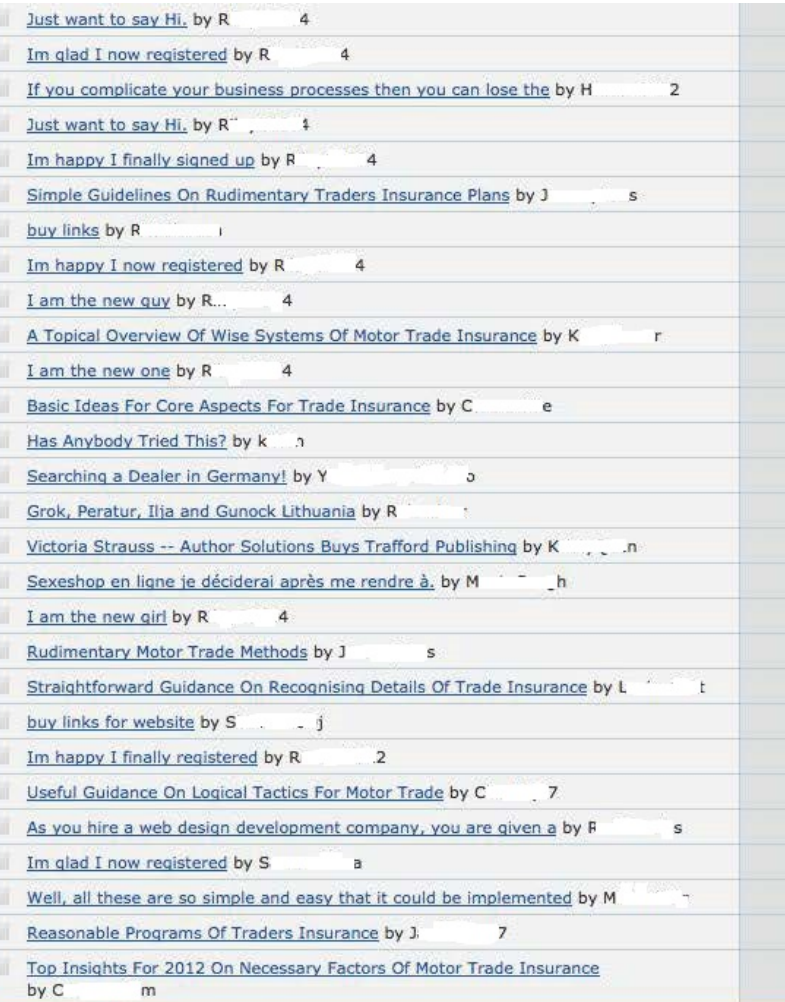

\begin{tabular}{|c|c|}
\hline 2015-05-27 17:33:19 by $R$ & 4 \\
\hline 2015-05-27 17:20:56 by $\mathrm{F}$ & 4 \\
\hline 2015-05-27 17:18:59 by $\mathrm{H}$ & 2 \\
\hline$\underline{2015-05-2717: 02: 12}$ by $R$ & 4 \\
\hline 2015-05-27 16:54:51 by $R$ & 4 \\
\hline$\underline{2015-05-2716: 42: 09}$ by $]$ & s \\
\hline$\underline{2015-05-2716: 38: 50}$ by $R$ & n \\
\hline 2015-05-27 16:12:30 by $R$ & 4 \\
\hline 2015-05-27 15:55:30 by $R$ & 1 \\
\hline$\underline{2015-05-27 \quad 15: 40: 54}$ by $\mathrm{K}$ & $r$ \\
\hline$\underline{2015-05-27 \quad 15: 35: 21}$ by $R$ & + \\
\hline$\underline{2015-05-2715: 29: 59}$ by C & e \\
\hline 2015-05-27 15:15:52 by $R$ & $r$ \\
\hline 2015-05-27 15:10:38 by $R$ & ir \\
\hline 2015-05-27 15:03:47 by $R$ & $r$ \\
\hline 2015-05-27 15:02:02 by $\mathrm{K}$ & $n$ \\
\hline $2015-05-2714: 58: 05$ by $M$ & h \\
\hline$\underline{2015-05-2714: 51: 52}$ by $R$ & 4 \\
\hline 2015-05-27 14:22:28 by 3 & s \\
\hline$\underline{2015-05-27 \quad 14: 15: 25}$ by L & $\mathrm{t}$ \\
\hline 2015-05-27 14:13:43 by $S$ & j \\
\hline 2015-05-27 13:43:18 by $R$ & 2 \\
\hline 2015-05-27 13:43:17 by C.. & $\cdot$ \\
\hline$\underline{2015-05-2713: 40: 18}$ by $R$ & s \\
\hline 2015-05-27 13:39:57 by S. & :a \\
\hline 2015-05-27 13:39:17 by $M$ & $r$ \\
\hline$\underline{2015-05-2713: 35: 26}$ by $\mathrm{J}$ & 7 \\
\hline 2015-05-27 13:31:33 by C & $\mathrm{m}$ \\
\hline
\end{tabular}

\section{figure 2. Trash postings}

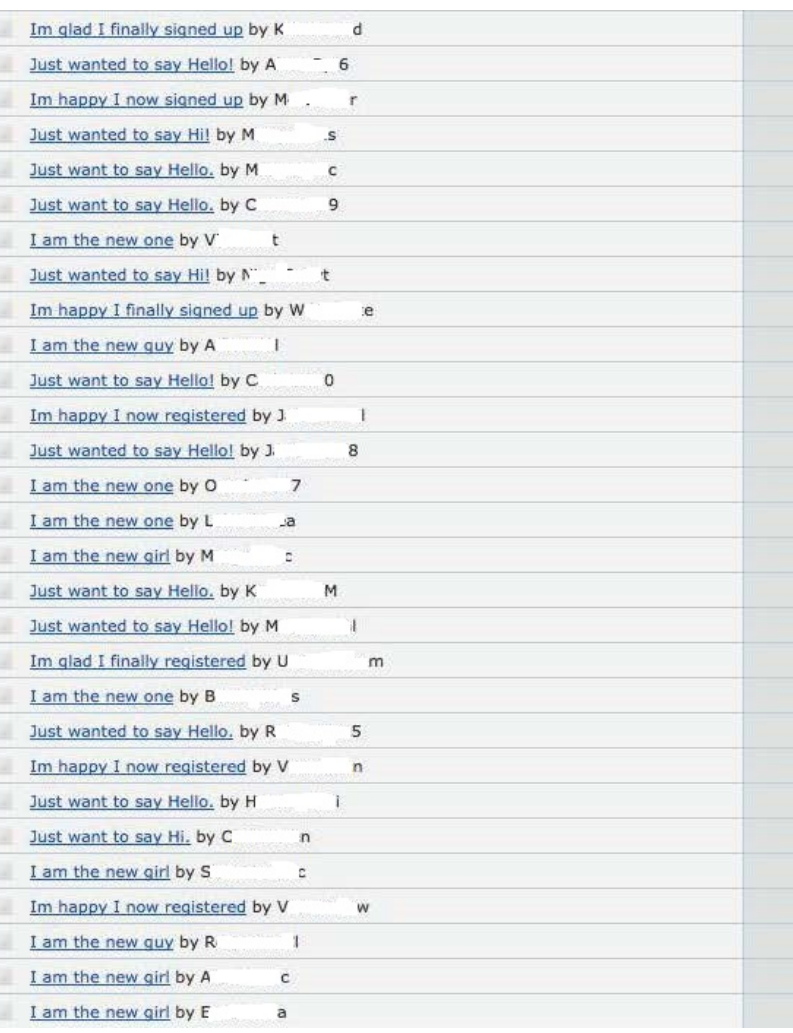

\begin{tabular}{|l|l}
\hline 177 \\
\hline 173 \\
\hline 170 \\
\hline 166 \\
159 \\
\hline 175 \\
\hline 165 \\
\hline 229 \\
\hline 158 \\
\hline 161 \\
\hline 148 \\
\hline 143 \\
\hline 145 \\
\hline 147 \\
\hline 144 \\
\hline 164 \\
\hline 145 \\
\hline 160 \\
\hline 148 \\
\hline 144 \\
\hline 210 \\
\hline 144 \\
\hline 151 \\
\hline 156 \\
\hline 152 \\
\hline 143 \\
\hline 148 \\
\hline 174 \\
\hline
\end{tabular}

\begin{tabular}{|c|c|}
\hline 2015-06-03 20:13:43 by $K$ & d \\
\hline 2015-06-03 20:05:33 by $A$ & 6 \\
\hline 2015-06-03 20:04:19 by $M$ & $r$ \\
\hline 2015-06-03 19:58:22 by $M$ & s \\
\hline 2015-06-03 19:50:10 by M & $=$ \\
\hline$\underline{2015-06-03 \quad 19: 44: 16}$ by $\mathrm{C}$ & 9 \\
\hline 2015-06-03 19:20:04 by V & $t$ \\
\hline 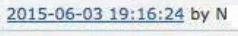 & t \\
\hline 2015-06-03 19:16:15 by $W$ & e \\
\hline 2015-06-03 19:10:19 by A & 1 \\
\hline 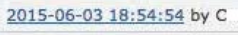 & 0 \\
\hline 2015-06-03 18:34:53 by ? & 1 \\
\hline 2015-06-03 18:32:05 by J & 8 \\
\hline 2015-06-03 18:28:50 by 0 & 7 \\
\hline 2015-06-03 18:17:23 by L &. \\
\hline 2015-06-03 17:58:51 by M & c \\
\hline 2015-06-03 17:53:26 by $\mathrm{K}$ & M \\
\hline 2015-06-03 17:49:52 by $M$ & 1 \\
\hline 2015-06-03 17:40:32 by U & $n$ \\
\hline 2015-06-03 17:35:15 by B & s \\
\hline 2015-06-03 17:29:13 by $R$ & 5 \\
\hline 2015-06-03 17:26:29 by V & $n$ \\
\hline 2015-06-03 17:03:10 by H & $i$ \\
\hline 2015-06-03 16:57:28 by C & n \\
\hline 2015-06-03 16:53:57 by S & $=$ \\
\hline 2015-06-03 16:53:30 by $\mathrm{V}$ & $v$ \\
\hline 2015-06-03 16:41:40 by $R$ & 1 \\
\hline 2015-06-03 16:33:15 by A & c \\
\hline 2015-06-03 16:29:15 by $E$ & a \\
\hline
\end{tabular}

figure 3. Trash postings

This is an unfortunate context for a new user with a genuine question to wade into as many of the spam posts contain headers of an introductory nature. However, posts we have coded as liminal are rarely moved to the 'trash folders'. In this post the author shares unarticulated worries and or general bewilderment about using cryptomarkets, as follows in the exchange 
between dD' (post count $=1$ ), g' (post count $=678$ ), $\mathrm{mH}^{\prime}$ (post count $=1,424$ ), and $m R^{\prime}$ (post count $=157)$ :

dD': I'm dD' and I want to buy cannabis eventually using this market. I'm kind of sceptical, this will be my first purchase on any DW site and have a few questions if you don't mind answering them.

1. If I buy the cannabis, how long until I can expect delivery?

2. How will they pack the cannabis so it gets through security?

3. What vendors are trustable and what is the likelihood of being scammed?

g': Read around the forum mate or do you want us to smoke it for you as well lol

$\mathrm{mH}^{\prime}$ : 1. Different for different vendors within a week usually

2. vacuum sealed in some sort of stealth way (won't go into details on specific vendor's stealth)

3. Search forums or marketplaces for high level members with lots of good reviews

mR': Check out drugs discussion threads for info, cannabis section.

We coded this interaction as liminal for a few reasons. First, the post count of the fora contributors may indicate the depth of experience the different authors have with the cryptomarkets. The post counts are true of the time of observation, not of the time that each contributor posted. This does not detract from the argument that this is an interaction between a new user and seasoned hands, and it strengthens the argument that this is indeed a liminal interaction, as dD' does not continue posting on the fora after this interaction. Second, there is the content of dD's questions. These are all questions that are essentially asking how does this thing work? Third, the responses from the regular contributors in the form of a combination of the bare minimum of informative data, instructions on where to go about finding this information, and light derision.

Their interaction also relates to the constructs of the ethos of self-reliance and the performative self-reliance that we discussed earlier. The interaction between liminality and self-reliance manifests here as antithetical. dD's post comes up against the ethos of self-reliance by actively seeking guidance and in so doing bringing to a head that self-reliance alone will not be sufficient to successfully use cryptomarkets. The performative self-reliance construct is then relevant to the responses to dD's post, both in the command forms of "read", "search", "check out" all saying find out for yourself, and the sarcastic "do you want us to smoke it for you as well?" This is performative self-reliance as it obfuscates the work of others in the utilisation process in the form of an instruction to go and discover for yourself what has already been drafted and published by others for you to read.

\section{Discussion}

Our themes of research, window-shopping and spread the word are all action-based practices that are relatively straightforward and are for the most part complementary. They are also arguably consequences of our theme of segregation, which relates to the level of difficulty involved in accessing and navigating the cryptomarkets. Segregation of cryptomarkets to the darknet may be constructed as a barrier to growth; however, as the technologies involved have progressed since 2011 this segregation simply mandates installing one more software application for the average buyer. We argue that it is the segregation of knowledge that must 
be overcome. The tension between liminality and self-reliance illustrates the problematic nature of a guideless platform. As much as cryptomarkets can be thought of as liminal places, they can surely be thought of as self-reliant places as well, and as we have previously discussed these two concepts are difficult to reconcile.

The constructs of self-reliance we coded for in the interviews could possibly also be interpreted as the products of asking cryptomarket users to explain how they use cryptomarkets, thereby centring their actions, expertise, and experience. A similar process may also be at play in the fora exchanges when requests for guidance and advice are posted, again centring the presumed expertise of the people who are to respond. While these environments may be conducive to the constructions of centred narratives, they do not dictate them. We argue that the relationship between self-reliance and cryptomarkets can be constructed and observed throughout the different sites and points of interaction between the cryptomarket users and the cryptomarkets. There is scope to explore further how values such as these are operationalised and capitalised on in cryptomarkets and add to Maddox et al.'s work on how they may appeal to cryptomarket users (Maddox et al., 2016).

The environment that we have discussed here does not easily translate into a smooth technological acceptance path. Rather, the breadth of knowledge and expertise required and the ethos of self-reliance running throughout make it unlikely that the technology will become widely used if nothing changes.

On first encounter the individual is encouraged by both direct instructions and a lack of other options to study first and sign up later; or, as we have shown, invest time, energy and resources in investigating every possible scenario related to the cryptomarkets environment, and only then start using the platform. This process is at odds with the procedural welcoming employed by many other e-commerce platforms today, which entice and guide the customer through their experience (Germanakos \& Belk, 2016). Instead of potential customers being able to view all the offerings and access all the necessary information about a product before they are required to commit anything to the process, as common on eBay or Amazon, wouldbe cryptomarket users must first create a username and register with the site. In a very real way prospective cryptomarket users are required to contribute to cryptomarkets by increasing the number of registered users before they receive anything, such as basic information, from the cryptomarkets. To make matters worse from an acceptance perspective, the operators of the cryptomarkets themselves do not seem outwardly concerned with directly educating the people who use their services and are instead relying on them to educate themselves. This perception is cultivated by a noted absence of actual guides produced and hosted by the cryptomarkets themselves, or demonstrative tours of the site programmed to run during an individual's first visit. The arguable usefulness of an ethos like self-reliance to an enterprise like the cryptomarkets can only go so far. The tensions we presented through the constructs of performative self-reliance can send a downright confusing message to would-be cryptomarket customers about whether cryptomarkets are serious about courting their business.

It is of course possible, and entirely probable, that cryptomarket administrators had a hand in many of the guides produced that at the time of observations were readily available on both the darknet and the clearnet, but there is still a difference between contributing to the dissemination of the data a prospective cryptomarket user will need to visit your site of business, and visibly helping your would-be visitors. That said, we were only able to include publicly performed interactions and the reflections of participants constructed during interviews in this analysis. Further ethnographic study of cryptomarkets could contribute greatly to our knowledge regarding many of the processes and practices we have tried to 
illuminate here, as well as looking directly at the acceptability of cryptomarkets as a viable competitive distribution model. This proposed line of study would also be able to look at the behaviours that would establish regular cryptomarket use. Although questions regarding these types of behaviours were included in the interview schedule used with participants, we think that these questions, and many more, will be better answered by an ethnography of cryptomarket users, rather than an ethnography of cryptomarket spaces. Future research may also explore why people do not use cryptomarkets, as well as further exploring the experiences of those who do.

On February 27th, 2018, the U.S. House of Representatives passed bill H.R. 1865 'Allow States and Victims to Fight Online Sex Trafficking Act (FOSTA)'. This bill allows for states and individuals to hold Internet platforms and websites liable for the actions of the users of the platforms and websites in the form of private or criminal charges, or both (Mullin, 2018). On March $21^{\text {st }}, 2018$ the U.S. Senate passed FOSTA, prompting closures of subreddits on Reddit, and the entire 'personals' section on Craigslist (Tracy, 2018). Although the U.S. bill currently specifies language related to sex work, Reddit has banned the largest darknet-related subreddits at the same time (Aliens, 2018). The Reddit darknet market (cryptomarket) related subreddits were an integral space in the cryptomarket environment. They were an accessible home to many of the guides, tutorials, reviews and information that constituted participants' research and window-shopping. What happens next remains to be seen. Will a different clearnet site take on this hosting role, or will the information find its way back to Reddit? Will cryptomarket use become dependent on personal connections instead of freely available information? Will this prompt cryptomarkets to take a more active role in the recruitment and provision of information to new actors? Or could this possibly be the beginning of the end for cryptomarkets? It is too soon to tell if this is even a watershed moment for cryptomarkets however, it is an opportune moment for a radical change to the current environment. Any such changes are likely to have an effect on the 'ease of use' measures for cryptomarkets and therefore the likelihood of widespread cryptomarket usage in the future.

\section{References:}

Aldridge, J., \& Décary-Hétu, D. (2014). Not an 'Ebay for Drugs': The cryptomarket 'Silk Road' as a paradigm shifting ciminal intervention. Available at SSRN:

http://www.webcitation.org/76T4rOUTD

Aldridge, J., \& Décary-Hétu, D. (2015). Cryptomarkets: The Darknet As An Online Drug Market Innovation. Retrieved from: https://daviddhetu.openum.ca/files/sites/39/2017/04/Nesta-Final-Report.pdf

Aldridge, J., \& Décary-Hétu, D. (2016). Hidden wholesale: The drug diffusing capacity of online drug cryptomarkets. International Journal of Drug Policy, 35, 7-15.

Aldridge, J., Stevens, A., \& Barratt, M. J. (2018. Will growth in cryptomarket drug buying increase the harms of illicit drugs? Addiction, 113(5), 789-796.

Aliens, C. (2018). Reddit Just Banned /R/DarkNetmarkets - Biggest Darknet Subreddit. Retrieved from: http://www.webcitation.org/76T5FpXLC

Bancroft, A. (2017). Responsible use to responsible harm: illicit drug use and peer harm reduction in a darknet cryptomarket. Health, risk \& society, 19(7-8), 336-350.

Barratt, M. J. (2012). Silk Road: eBay for drugs. Addiction, 107(3), 683.

Barratt, M. J., \& Aldridge, J. (2016). Everything you always wanted to know about drug cryptomarkets ${ }^{*}{ }^{*}$ but were afraid to ask). International Journal of Drug Policy, 35, 1-6.

Bearman, J \& Hanuka, T. (2015). The Rise \& Fall of Silk Road. Wired. Retrieved from: http://www.webcitation.org/76T5J7Zsj

Boon, E., Pitt, L., \& Salehi-Sangari, E. (2015). Managing information sharing in online communities and marketplaces. Business Horizons, 58(3), 347-353. 
Braun, V., \& Clarke, V. (2013). Successful qualitative research: A practical guide for beginners. London, UK: Sage.

Broséus, J., Morelato, M., Tahtouh, M., \& Roux, C. (2017). Forensic drug intelligence and the rise of cryptomarkets. Part I: Studying the Australian virtual market. Forensic science international, 279, 288-301.

Charmaz, K. \& Olesen, V. (1997). Ethnographic research in medical sociology: Its foci and distinctive contributions. Sociological methods \& research, 25(4), 452-494.

Charmaz, K. (2014). Constructing Grounded Theory ( $2^{\text {nd }}$ ed.). Los Angeles, California: Sage.

Clouston Paquet, C. M. (2017). Are Cryptomarkets the Future of Drug Dealing? Assessing the Structure of the Drug Market Hosted on Cryptomarkets (thesis). Retrived from: http://www.webcitation.org/76T5c2gx9

Décary-Hétu, D., \& Giommoni, L. (2017). Do police crackdowns disrupt drug cryptomarkets? A longitudinal analysis of the effects of Operation Onymous. Crime, Law and Social Change, 67(1), 55-75.

Demant, J., Munksgaard, R., \& Houborg, E. (2018). Personal use, social supply or redistribution? Cryptomarket demand on Silk Road 2 and Agora. Trends in Organized Crime, 21(1), 42-61.

Dolliver, D. S., Ericson, S. P., \& Love, K. L. (2018). A geographic analysis of drug trafficking patterns on the tor network. Geographical Review, 108(1), 45-68.

Emerson, R. W. (1902). So this Then is the Essay on Self-reliance. Charleston, South Carolina: Nabu Press

Emerson, R.M., Fretz, R.I. \& Shaw, L.L. (1995). Writing ethnographic fieldnotes. Chicago, Illinois: The University of Chicago Press.

Germanakos, P., \& Belk, M. (2016). Human-Centred Web Adaptation and Personalization: From Theory to Practice. Cham, Switzerland: Springer International Publishing.

Griffiths, P., \& Mounteney, J. (2017). Disruptive Potential of the Internet to Transform Illicit Drug Markets and Impact on Future Patterns of Drug Consumption. Clinical Pharmacology \& Therapeutics, 101(2), 176-178.

Klara, R. (2017). Bad news, brick-and-mortar stores: the internet finally has you beat. ADWEEK. Retrieved from: http://www.webcitation.org/76T6BK4vS

Ladegaard, I. (2017). "I Pray That We Will Find a Way to Carry on This Dream": How a Law Enforcement Crackdown United an Online Community. Critical Sociology. Retrieved from:

https://journals.sagepub.com/doi/abs/10.1177/0896920517735670\#articleCitationDo wnloadContainer

Mac, R. (2013). Who Is Ross Ulbricht? Piecing Together The Life Of The Alleged Libertarian Mastermind Behind Silk Road. Forbes. Retrieved from:

http://www.webcitation.org/76T6VKBya

Maddox, A., Barratt, M. J., Allen, M., \& Lenton, S. (2016). Constructive activism in the dark web: cryptomarkets and illicit drugs in the digital 'demimonde'. Information, Communication and Society, 19, 111-126.

Martin, J. (2014). Drugs on the dark net: How cryptomarkets are transforming the global trade in illicit drugs. UK: Palgrave Macmillan.

Martin, J., \& Christin, N. (2016). Ethics in cryptomarket research. International Journal of Drug Policy, 35, 84-91.

May, C. (2017). Transnational Crime and the Developing World. Washington, District of Columbia: Global Financial Integrity.

Morse, J. M. (1994). Emerging from the data: The cognitive processes of analysis in qualitative inquiry. In J.M. Morse (Ed), Critical issues in qualitative research methods (23-43). Thousand Oaks, California: Sage Publications

Mullin, J. (2018). House Vote on FOSTA is a Win for Censorship. Retrieved from: http://www.webcitation.org/76T72m6kF

Page, J. B., \& Singer, M. (2010). Comprehending drug use: Ethnographic research at the social margins. New Brunswick, New Jersey: Rutgers University Press. 
Paquet-Clouston, M., Décary-Hétu, D., \& Morselli, C. (2018). Assessing market competition and vendors; size and scope on AlphaBay. International Journal of Drug Policy, 54, 87-98.

Roper, J. M., \& Shapira, J. (2000). Ethnography in nursing research (Vol. 1). Thousand Oaks, California: Sage.

Sixsmith, J., \& Murray, C. D. (2001). Ethical Issues in the Documentary Data Analysis of Internet Posts and Archives. Qualitative Health Research, 11(3), 423-432.

Sotirakopoulos, N. (2018). Cryptomarkets as a libertarian counter-conduct of resistance. European Journal of Social Theory, 21(2), 189-206.

Tracy, P. (2018). Trump signs controversial 'sex trafficking' bill that could hurt the future of the internet. Retrieved from: http://www.webcitation.org/76T7bWpsQ

Turner, V. (1987). Betwixt and between: The liminal period in rites of passage. In L.C. Mahdi, S. Foster, M. Little (Ed), Betwixt and between: Patterns of masculine and feminine initiation (3-19). LA Salle, Illinois: Open Court.

Tzanetakis, M. (2018). Comparing cryptomarkets for drugs. A characterisation of sellers and buyers over time. International Journal of Drug Policy, 56, 176-186.

United Nations Office on Drugs and Crime. (2018). World Drug Report 2018. Vienna: United Nations.

Van Buskirk, J., Naicker, S., Roxburgh, A., Bruno, R., \& Burns, L. (2016). Who sells what? Country specific differences in substance availability on the Agora cryptomarket. International Journal of Drug Policy, 35, 16-23.

Van Gennep, A. (2013). The rites of passage. London, UK: Routledge.

Venkatesh, V., \& Davis, F. D. (2000). A theoretical extension of the technology acceptance model: Four longitudinal field studies. Management science, 46(2), 186-204. 